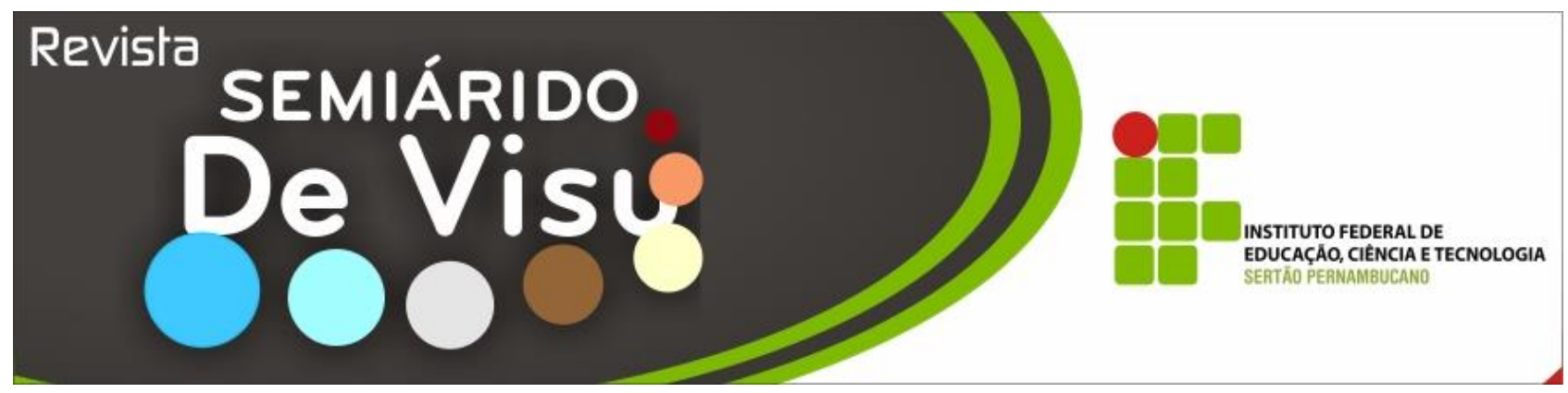

\title{
REVISÃO SISTEMÁTICA EM REVISTAS DA PLATAFORMA CAPES SOBRE LETRAMENTO(S) EM LÍNGUA ESPANHOLA NA REDE TÉCNICA E PROFISSIONALIZANTE
}

\author{
Kélvya Freitas Abreu ${ }^{1}$, Jiovana Katarina Carvalho de Oliveira ${ }^{2}$, Francisco Kelsen de Oliveira ${ }^{3}$
}

\begin{abstract}
${ }^{1}$ Docente da coordenação propedêutica e orientadora do PIBIC Jr.; ${ }^{2}$ Discente do curso de Ensino Médio Integrado em Edificações e bolsista do projeto PIBIC Jr.; ${ }^{3}$ Docente da Coordenação de Informática e co-orientador do projeto PIBIC Jr. Instituto Federal de Educação, Ciência e Tecnologia do Sertão Pernambucano - campus Salgueiro. BR 232, Km 508, sentido Recife, Zona Rural - Salgueiro - PE - Brasil. CEP: 56.000-000 E-mail: ${ }^{1}$ kelvya.freitas@ifsertao-pe.edu.br; ${ }^{2}$ jiovanak@hotmail.com; ${ }^{3}$ francisco.oliveira@ifsertao-pe.edu.br;
\end{abstract}

RESUMO: O presente artigo tem como objetivo apresentar um mapeamento sistemático realizado em revistas publicadas no período de 2008 a 2014, coletadas através da Plataforma Sucupira - Capes, a fim de analisar se o conceito de Letramento entrelaçado ao ensino de Espanhol como Língua Estrangeira (ELE) está sendo abordado em trabalhos científicos no contexto do ensino técnico tecnológico do país, ou seja, na rede técnica profissionalizante, em especial da rede pública. Assim sendo, para tal análise, fez-se uma Revisão Sistemática da Literatura (RSL), em que tais revistas foram analisadas através de termos-chaves utilizados especificamente para a busca de trabalhos que englobam tal temática. Logo, obteve-se um resultado percentual sobre a quantidade de trabalhos envolvidos na perspectiva do Letramento e do ELE, propiciando discussões sobre as lacunas expressas nesse contexto educacional, uma vez que, respeitando-se o recorte dado, não fora encontrado nenhum artigo dentro do escopo desta investigação. Por fim, o presente trabalho pautou o estudo sob o conceito da pedagogia dos letramentos na perspectiva teórica proposta por Soares (2005), Cassany (2006), Rojo (2009) e Street, (2010), de igual forma, trabalhou com a perspectiva do Ensino do Espanhol como Língua Estrangeira apresentada por Baptista (2010), como também abordou o desenvolvimento da RSL por Oliveira e Gomes (2015) e o panorama do ensino técnico pelas Diretrizes Curriculares Nacionais da Educação Básica (2013).

Palavras-chave: Multiletramentos; Espanhol como Língua Estrangeira; Ensino Técnico Tecnológico.

\section{SYSTEMATIC REVIEW IN JOURNALS OF THE PLATAFORMA CAPES ABOUT LITERACIES IN SPANISH LANGUAGE ON THE TECHNICAL AND PROFESSIONAL NETWORK}

\begin{abstract}
The present article aims to present a systematic mapping of journals published from 2008 to 2014 , collected through the Plataforma Sucupira - Capes, in order to analyze whether the concept of Literacy intertwined with the teaching of Spanish as a Foreign Language is being addressed in scientific work in the context of technical education of our country, that is, in the professional technical network, especially the public network. Thus, for such analysis, a Systematic Review of Literature (RSL) was done, in which such journals were analyzed through key terms used specifically for the search of works that encompass this theme. Therefore, a percentage result was obtained on the amount of work involved in the perspective of Literacy and the Spanish as a Foreign Language, providing discussions about the possible shortcomings expressed in this educational context. Finally, the present work guided the study under the concept of the pedagogy of literacy in the theoretical perspective proposed by Soares (2005), Cassany (2006), Rojo (2009) and Street, (2010), likewise worked with perspective of the Spanish as a Foreign Language presented by Baptista (2010), as well as the development of RSL by Oliveira and Gomes (2015) and the technical education landscape by the Diretrizes Curriculares Nacionais da Educação Básica (2013).
\end{abstract}

keywords: Multiple Literacies; Spanish as a Foreign Language; Technical Technological Teaching 


\section{Considerações Iniciais}

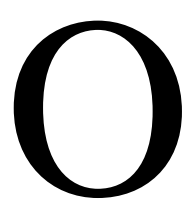

ser humano, a cada dia que passa, transforma o meio em que vive e, principalmente, a forma como se comunica. Não diferentemente, o cenário educacional também se recria e avança em estudos e pesquisas em torno de novas concepções, por exemplo, voltadas para aprendizagem da escrita e da leitura diante dessa transformação contínua de nossa sociedade. A partir da dinamicidade da vida em comunidade, caracterizada, especialmente, pelo vasto desenvolvimento no campo das ciências e da tecnologia, o cenário educacional também se modifica, já que, ao longo dos tempos, metodologias de ensino são analisadas e reavaliadas, e como consequência geram também impactos em documentos governamentais que orientam esse mesmo contexto educacional.

É nessa concepção de transformações
sociais que alguns docentes estão progressivamente em busca de novas formas de produzir e transmitir conhecimento (ABREU, IRINEU, BAPTISTA, 2010), com a finalidade de motivar alunos na busca autônoma por conhecimento e de despertar nesses discentes uma visão crítica-reflexiva em relação ao meio em que vivem. Além disso, tais profissionais são incentivados a nortearem sua prática educacional fundamentados na Lei de Diretrizes e Bases n9394/96 (LDB, BRASIL, 1996), na qual o artigo 22 destaca: "A educação básica tem por finalidades desenvolver $\mathrm{o}$ educando, assegurar-lhe a formação comum indispensável para o exercício da cidadania e fornecer-lhe meios para progredir no trabalho e em estudos posteriores", ou seja, o ensino deve ter como principal objetivo preparar o educando para agir nas diversas instâncias da sociedade, principalmente na instância profissional $^{1}$. Dessa maneira, pode-se destacar por exemplo, trabalhos científicos, ensaios em laboratórios e pesquisas em comunidades como práticas escolares que promovem o saber e que

\footnotetext{
1 Apesar das alterações propostas por meio da Lei $\mathrm{n}^{\circ} 13.145$ de 2017 que altera a LDB e institui a atual política do "novo ensino médio".
}

motivam o aluno a participar das atividades propostas em sala de aula.

Portanto, nesse cenário, o conceito de Letramento surge como aliado ao de formação cidadã, já que tal abordagem de ensino envolve práticas educacionais entrelaçadas ao cotidiano de discentes. Essa perspectiva pode ser interpretada em uma dimensão individual, na qual o cidadão busca, de forma autônoma, apreender as habilidades de leitura e escrita; e, por outro lado, por uma dimensão social, em que busca colocar em prática tais habilidades de leitura e de escrita com os demais sujeitos, atuando no e para o mundo, por meio de práticas e eventos de linguagem. Isso posto, na concepção de que "a escrita traz consequências sociais, culturais, políticas, econômicas, cognitivas, linguísticas, quer para o grupo social em que seja introduzida, quer para o indivíduo que aprenda a usá-la" (SOARES, 2005), analisa-se que um indivíduo letrado pode possivelmente apresentar uma visão de mundo diferente, já que interpreta a realidade em relação à uma condição social e cultural em um ponto de vista mais crítico, fazendo com que o mesmo possa até mudar suas ações em sociedade e aprimorar o seu desenvolvimento pessoal (STREET, 2010).

Logo, percebe-se que o letramento é uma perspectiva de ensino que visa o desenvolvimento social em suas práticas, já que apresenta como finalidade a formação de um sujeito crítico que age de forma ativa na sociedade e que é consciente das diferentes culturas na qual está em contato. Além disso, pode ser caracterizada também como contribuinte para a formação de bons profissionais para a sociedade, considerando-se que em suas práticas sociais da leitura e da escrita, ao não apenas centrar-se na codificação e decodificação de textos, possibilita práticas necessárias para o educando agir no seu ambiente de trabalho (OLIVEIRA, SOARES, ABREU, CORREIA, 2016), especialmente porque o ambiente profissional é caracterizado por ser competitivo que busca indivíduos autônomos preparados para atuar com segurança nas diferentes relações profissionais, além de posturas críticas, éticas e cidadãs. 
Dessa forma, neste trabalho, analisou-se como o conceito de letramento é abordado em trabalhos científicos apresentados em revistas publicadas no período de 2008 a 2014 nos periódicos nacionais. A escolha desse período se justifica por conta da implementação da Lei dos Institutos Federais ${ }^{2}$ e da Lei do Espanhol $^{3}$ (essa já extinta) ${ }^{4}$. Nesse caso, foram analisados, por um lado, por trabalhos que apresentam o estudo do letramento no contexto dos Institutos Federais do país, tendo em vista que esses, além de garantirem o ensino médio, disponibilizam o curso técnico profissionalizante; e, por outro lado, visou-se analisar a presença do conceito de letramento relacionado à perspectiva do ensino da Língua Espanhola como Língua Estrangeira (ELE), já que o processo de ensino e aprendizagem de um idioma deve estar entrelaçado à sociedade que o discente está inserido, para que assim se possa ocorrer uma relação entre sua realidade e o contexto da língua que está sendo trabalhada. Em síntese nossa proposta era compreender esse cenário, conforme figura 1 .

Figura 1 - Relações entre letramentos, ensino técnico e ensino de espanhol como LE

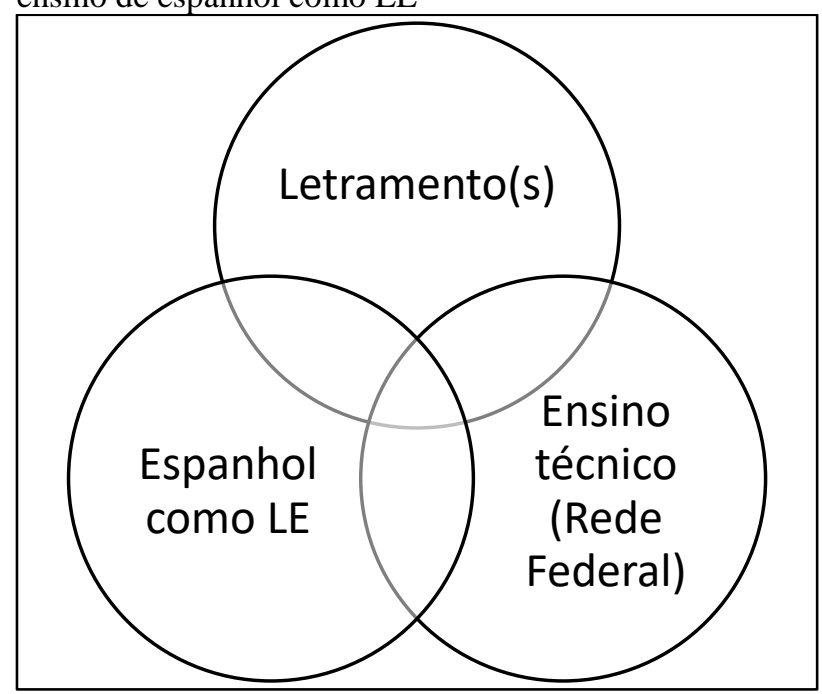

Fonte: Elaborado pelos autores.

2 http://www.planalto.gov.br/ccivil_03/_ato20072010/2008/lei/111892.htm

3 http://www.planalto.gov.br/ccivil_03/_ato20042006/2005/lei/111161.htm

${ }^{4}$ Em virtude do propósito do artigo, não se adentrará nas análises dos pontos alterados pela MP nº746/16. Para maiores http://www.planalto.gov.br/ccivil_03/_ato2015informações:

2018/2016/Mpv/mpv746.htm Acessado em: 30/09/16
Cumpre destacar que o ensino de um idioma, na perspectiva do Letramento, torna-se um processo que vai além da aprendizagem para comunicação por meio de elementos gramaticais e linguísticos, pois envolve fatores que despertam o senso crítico do discente e fazem-lhe interagir socialmente, respeitando as culturas e as ideologias do entorno social imposto pelo idioma (BAPTISTA, 2010). Nesse sentido, o ensino do Espanhol faz-se importante para o conhecimento de culturas diferentes e, consequentemente, para uma maior inclusão social dos cidadãos em suas práticas sociais, seja na escola, seja no ambiente de trabalho.

Os principais parâmetros dessa pesquisa, o espanhol como língua estrangeira, o ensino técnico tecnológico e a perspectiva dos letramentos, associados aos métodos utilizados para efetivar o presente estudo, serão abordados de forma mais específica nas seções seguintes.

\section{Espanhol como Língua Estrangeira}

Conforme exposto, outro ponto que justifica o presente trabalho é o fato de entretecer a educação profissional em suas práticas e eventos de letramento(s) com a língua espanhola no cenário de pesquisas brasileiras. Para tal, cumpre ressaltar o que sinaliza Abreu (2011), pois com a publicação da LDB (BRASIL, 1996) foi reformulada a atenção dada até então ao ensino de uma língua estrangeira (LE), uma vez que o fato de aprender um idioma era associado apenas a uma atividade complementar e sem "relevância na construção da identidade do aprendiz" (ABREU, 2011, p.23). Assim sendo, repensa-se e propõe-se um novo status ao ensino de LE moderna ao compreendê-la como uma disciplina do saber que apoia a formação cidadã do alunado. Além disso, com a publicação da Lei 11.161/05, a disciplina de língua espanhola passou a ter o caráter de oferta obrigatória no ensino médio nos últimos dez anos (2005 09/2016). Não obstante, a língua de Cervantes veio ganhando relevo e conforme expõe em capítulo específico para o ensino de língua espanhola nas OCNEM (BRASIL, 2006), o espanhol foi compreendido no processo 
educativo como carregado de significados e valores, devendo os estudantes serem expostos ao processo de alteridade, de diversidade, de heterogeneidade, pois esse é o "caminho fértil para a construção da sua identidade" em um dado idioma (Idem, 2006, p. 129).

Assim, uma forma de ensino que relacione fatores sociais, políticos e culturais, faz-se importante para o desenvolvimento da formação cidadã de indivíduos, principalmente em relação ao ensino de línguas estrangeiras, já que promovem experiências de contato com a da constituição de um povo e seus costumes, como também de uma nova cultura e de um novo discurso.

Diante disso, vale sinalizar que a primeira referência a língua espanhola na rede de ensino foi em 1919 no Colégio Pedro II, porém o espanhol, como LE obrigatória nos currículos (Lei Orgânica do Ensino Secundário, 1942), só surgiu com a Reforma de Capanema, período que se caracterizou pela reestruturação da educação nacional. Por conseguinte, essa perspectiva de 1942 foi modificada com a Lei de Diretrizes e Bases da Educação instaurada em 1961, em que não apresentava nenhuma referência ao ensino de língua estrangeira em seu contexto, mas que criou os Conselhos Estaduais de Educação (CEE's) que passaram a ser um dos responsáveis pela organização da estrutura curricular, tendo o direito de determinar disciplinas que poderiam ser optativas ou obrigatórias.

Ainda assim, o espanhol teve menor poder de adesão nessa estrutura curricular estabelecida, o que foi um dos fatores que contribuíram para a pouca presença dessa língua nos currículos das escolas brasileiras. Nesse sentido, percebe-se que a LDB de 1961 foi a principal responsável pela modificação no cenário de ensino de línguas estrangeiras, sendo restaurado apenas em $1971 \mathrm{com}$ a nova lei, que trazia o ensino da língua estrangeira como uma sugestão de disciplina aos CEE's.

Já em relação a LDB instaurada em 1996, determinou-se a inclusão de uma língua estrangeira moderna como disciplina obrigatória, assim como também uma segunda como caráter optativo. Tal característica contribuiu essencialmente para a aprovação da
Lei $\mathrm{N}^{\circ} 11.161 / 2005$ apresentada pelo deputado Átila Lira ao congresso Nacional, a qual promoveu a diversificação da oferta de ensino de línguas no Ensino Médio, destacando o espanhol como disciplina de oferta obrigatória, como expresso no Artigo 1 da lei:

Art. lo O ensino da língua espanhola, de
oferta obrigatória pela escola e de
matrícula facultativa para o aluno, será
implantado, gradativamente, nos
currículos plenos do ensino médio.
§ 1 o O processo de implantação deverá
estar concluído no prazo de cinco anos, a
partir da implantação desta Lei.

Percebe-se que a Lei $\mathrm{N}^{\circ} 11.161 / 2005$, também conhecida como a "Lei do Espanhol", deveria ser implantada o ensino da Língua Espanhola no prazo de cinco anos, ou seja, até 2010. Contudo, por meio dessa lei era necessário que a oferta do ensino do espanhol no ensino médio estivesse totalmente implantado nas diversas escolas do país, processo esse que não ocorreu. Anos mais tarde, a própria Lei $\mathrm{N}^{\circ} 11.161 / 2005$ (Lei do Espanhol) foi revogada a partir da criação da Medida Provisória 746, conhecida como "reforma do ensino médio", tornando-se em 2017 a Lei $N^{\circ} 13.415$ ao determinar o espanhol como disciplina optativa, expresso no parágrafo 4 do Artigo $3^{\circ}$ :

$\S 4 o$ Os currículos do ensino médio
incluirão, obrigatoriamente, o estudo da
língua inglesa e poderão ofertar outras
línguas estrangeiras, em caráter optativo,
preferencialmente o espanhol, de acordo
com a disponibilidade de oferta, locais e
horários definidos pelos sistemas de
ensino.

Diversas questões surgem nesse cenário, em especial, pelo contexto de mundo globalizado em que vivemos, com a grande interação entre pessoas de diversas partes do mundo nas redes sociais e do desenvolvimento de relações internacionais no ambiente de trabalho. Mas por que o ensino da língua espanhola se tornar optativa no ensino básico se o Brasil é um país que faz parte da América Latina e faz fronteiras com países que tem 
como língua oficial o espanhol? Segundo Goettenauer (2005, p.62):

\begin{abstract}
Há muitos fatores vinculados ao ensino/aprendizagem de espanhol, não só aqueles que dizem respeito à própria prática educacional - objetivos, conteúdo, metodologia, material didático, recursos etc. -, mas também os que estão relacionados a considerações de outra ordem: os idiomas estão determinados pelos povos que os falam e pelas condições políticas, culturais e sociais em que esses povos vivem. Esta afirmação é ainda mais contundente quando se trata de uma língua falada em duas dezenas de países. É necessário levar em conta, além dos diversos espaços geográficos que influem nos modos e costumes de cada comunidade, as culturas, os sistemas político-econômicos, as organizações sociais, as histórias, o passado e o presente das várias nações, dos inúmeros povos e, ainda, os conflitos resultantes do contato do espanhol com outras línguas.
\end{abstract}

Assim como a língua inglesa é relevante, considerada por muitos "a língua universal", essencialmente devido a heranças do período industrial, como também é caracterizada por grandes potências como língua oficial, o espanhol faz-se necessário e importante na grade curricular de alunos que em um futuro próximo se tornarão trabalhadores e que são cidadãos, principalmente no contexto do Brasil, fazendo parte da América do Sul e da América Latina, onde se situa muitos países de língua espanhola. Em especial, porque o ensino de uma língua é muito importante para promover o contato entre diferentes aspectos culturais, nas instâncias relacionadas, por exemplo, à culinária, literatura, música, arte, entre outros. Além disso, garante a comunicação em diversas partes do mundo, já que o espanhol é a língua oficial de 21 países.

\section{A Rede Técnica Profissionalizante}

Diante dessa teia discursiva que este estudo tem como escopo costurar, parte-se da defesa que as formas de modalidades distintas (ensino regular e o ensino técnico profissionalizante da educação básica) no ensino médio podem reconfigurar a agência de letramento em seus modelos de letramentos, uma vez que no ensino técnico profissionalizante estar-se-á a frente de outro cenário com objetivos distintos. Logo, o papel sociohistórico das práticas ganha perfis na relação de produção e consumo de linguagem não homogêneos.

Deste modo, será necessário primeiro compreender e ressaltar que o ensino técnico da Educação Profissional Técnica de Nível Médio possui como princípio norteador articular a “formação desenvolvida no Ensino Médio e a preparação para o exercício das profissões técnicas, visando à formação integral do estudante" (inciso I, art. $6^{\mathbf{0}}$ - Resolução n06/2012 da CNE/CEB), além de indissociabilizar a educação com a prática social que estão inseridos. Logo, o caráter de intervenção social promovido pelas Diretrizes Curriculares Nacionais para a Educação Profissional Técnica de Nível Médio é um dos fios que colaboram nessa costura, uma vez que ao associar na formação o viés de um pensamento crítico, engajado e sobretudo social na formação do sujeito faz alinhavar com a pedagogia dos letramentos (ROJO, 2012) na busca de um modelo ideológico do letramento.

Portanto, nota-se a lacuna apresentada, pois ao investigar a temática, encontram-se pesquisas feitas com temas tangenciais ao que ora é apresentado e levado como caráter de relevância e originalidade ao entender as peculiaridades do Ensino Médio Integrado (EMI) em suas práticas de letramentos (vide os resultados deste estudo). Logo, é necessário no ensino e aprendizagem de línguas, no caso de ELE, ampliar os estudos buscando compreender as especificidades desse contexto, considerando quais e como atendê-las (ALMEIDA FILHO, 2008, p.221).

Cabe, de igual modo, destacar que ao investigar o lugar de qualificação profissional, os saberes contextualizados e o engajamento discursivo proposto pelo sujeito, sob uma perspectiva de que o profissional se insira, participe e interaja com a área que atua em uma LE, poderá visualizar a que modelos de letramento(s) esse sujeito tem contato em sua 
formação. Neste sentido, o formador é impelido a compreender o aprendiz em uma ótica sociohistórica e que a forma de estudar do discente seja potencializado a aliar-se as possibilidades práticas do cotidiano.

Contudo, quais pesquisas já se encontram em andamento? Quais compreendem o cenário da rede profissional? Existem estudo relacionando essa tríade (ver figura 1)? São questionamentos que não se esgotam nesse artigo, mas que devem se aprofundar para demarcações de espaços e construções teóricas-metodológicas sobretudo no cenário de línguas dentro do ensino profissional.

Dessa forma, cabe destacar que a criação dos Institutos Federais de Educação, Ciência e Tecnologia (IFECT) é recente, datada de 2008. Contudo, a história da Rede Federal de Educação Profissional no Brasil surge em 1909, primeiramente com uma política voltada a classes desprovidas, visando uma qualificação profissional desta camada da população. Porém, atualmente a rede profissionalizante federal, em especial, "se configura como importante estrutura para que todas as pessoas tenham efetivo acesso às conquistas científicas e tecnológicas" (SOUZA, 2013, p.61), além da sua formação técnica. Logo, nas Concepções e Diretrizes dos IFECT (BRASIL, CDIF, 2008), enfatiza-se a vertente de transformar, enriquecer conhecimentos e modificar a vida social do lugar no qual se localiza. Esse perfil de transformação, atribuído a esse modelo de instituição, é decorrente do objetivo de ofertar uma educação de qualidade, cujo foco é perpassar não apenas a aquisição de códigos escritos, mas também uma visão crítica e um caráter de cidadania (ABREU; MORAIS; SILVA, 2014) aos níveis de educação que oferta.

Desde o início, os novos IFECT apresentaram o caráter de desenvolver "condições estruturais necessárias ao desenvolvimento educacional e socioeconômico do Brasil" (CDIF, 2008, p.5). Contudo, como salientam as Diretrizes Curriculares Nacionais da Educação Básica (BRASIL, 2013), não somente a rede federal, mas em capítulo específico e destinado à
Educação Profissional Técnica de Nível Médio, a nova realidade do mundo do trabalho faz com que o cenário educacional do ensino profissional esteja atento ao "desenvolvimento de conhecimentos, saberes e competências profissionais complexos" (p.206), para tal associa-se como direito inalienável ao cidadão a educação e ao conhecimento:

Atualmente, não se concebe uma
Educação Profissional identificada como
simples instrumento de política
assistencialista ou linear ajustamento às
demandas do mercado de trabalho, mas
sim como importante estratégia para que
os cidadãos tenham efetivo acesso às
conquistas científicas e tecnológicas da
sociedade. Impõe-se a superação do
enfoque tradicional da formação
profissional baseado apenas na
preparação para execução de um
determinado conjunto de tarefas a serem
executadas. A Educação Profissional
requer, além do domínio operacional de
um determinado fazer, a compreensão
global do processo produtivo, com a
apreensão do saber tecnológico, a
valorização da cultura do trabalho e a
mobilização dos valores necessários à
tomada de decisões no mundo do trabalho
(BRASIL, 2013, p. 209).

Deste modo, coaduna-se com o pensamento de Morais et.al (2016, p.140) ao refletir sobre a educação como meio de possibilitar a mudança em uma dada região, pois será possível por meio da educação profissional atribuir esse valor de transformação social, de inclusão e de democratização das oportunidades no Brasil.

\section{Material e métodos}

Esta pesquisa utilizou a Revisão Sistemática da Literatura (RSL) a partir do processo de identificação dos materiais e dos modelos propostos por Kitchenham e Charters (2007) e Oliveira e Gomes (2015; 2016). Para isso, foi elaborado o protocolo de RSL com os termos de busca (Quadro 1), que geraram os 
scripts $^{5}$ utilizados nas buscas (Quadro 2), cujos resultados obtidos nos materiais coletados buscaram responder aos questionamentos levantados no início da pesquisa (Quadro 3).

Contudo, vale destacar que a RSL foi utilizada nesta pesquisa como um procedimento metodológico, uma vez que é possível identificar, avaliar e interpretar todas as pesquisas disponíveis que sejam relevantes para uma dada questão de pesquisa ou fenômeno de interesse (OLIVEIRA; GOMES, 2015; KITCHENHAM; CHARTES, 2007). Deste modo, os estudos individuais que contribuem para uma RSL são chamados de estudos primários; ao passo que uma revisão sistemática é uma forma de estudo secundário (OLIVEIRA; GOMES, 2015; MARSHALL; BRERETON, 2013).

Assim sendo, a RSL possuiu a vantagem de realizar um estudo secundário a partir da identificação, coleta e organização de estudos primários em estudos empíricos que investigaram questões de pesquisa específicas, com o intuito de integrar e sistematizar evidências relacionadas a tal questão (OLIVEIRA; GOMES, 2016). Além disso, destaca-se que a RSL segue um protocolo de pesquisa a partir de uma metodologia confiável, rigorosa e auditável, bem como possibilita identificar as evidências e problemas existentes nos trabalhos publicados, de modo a contribuir com a comunidade científica ao apresentar tal compêndio sobre determinado assunto, sendo essas algumas das vantagens em relação a uma revisão tradicional da literatura.

Nessa linha de raciocínio, a presente RSL basicamente considerou três fases, a saber:

1. a identificação dos materiais nas bases de dados;

2. leitura dos títulos, resumos, abstracts e conclusões; e,

3. leitura dos artigos completos.

Por conseguinte, e para que se fosse realizado o objetivo deste estudo, elencaram-se

\footnotetext{
${ }^{5}$ São considerados os resultados das palavras-chaves da etapa anterior, e assim são criadas as combinações de buscas para dar prosseguimento a investigação.
}

as strings ou palavras-chaves para que fosse possível efetuar a primeira etapa da investigação, como se observa no quadro 1.

Quadro 1 - Termos selecionados para formação da string de busca.

\begin{tabular}{|l|l|l|}
\hline $\mathbf{1}^{a}$ Ordem & $\mathbf{2}^{\boldsymbol{a}}$ Ordem & $\mathbf{3}^{\text {a }}$ Ordem \\
\hline \multirow{3}{*}{ Letramento } & Ensino técnico; Ensino & Espanhol; \\
& $\begin{array}{l}\text { Profissionalizante; } \\
\text { Ensino técnico }\end{array}$ & $\begin{array}{l}\text { Língua } \\
\text { Espanhola; }\end{array}$ \\
& tecnológico; Ensino & Espanhol como \\
& Médio Integrado; & língua \\
& & estrangeira; \\
& & ELE; \\
\hline
\end{tabular}

Fonte: Adaptado (OLIVEIRA; GOMES, 2015, 2016).

Após a seleção dessas, realizou-se a strings de buscas nas revistas, conforme se expõe no quadro 2.

Quadro 2 - Scripts de buscas.

\begin{tabular}{|l|l|}
\hline ID & Script de busca \\
\hline S1 6 & ("Letramento") AND ("Ensino técnico" OR \\
& "Ensino Profissionalizante" OR "Ensino \\
& técnico tecnológico" OR "Ensino Médio \\
& Integrado") AND ("Espanhol" OR "Língua \\
& Espanhola" OR "Espanhol como lingua \\
& estrangeira" OR "ELE") AND (year>=2005).
\end{tabular}

Fonte: Adaptado (OLIVEIRA; GOMES, 2015, 2016).

Vale ressaltar que alguns questionamentos surgiram e que motivaram o presente estudo, haja vista que o letramento é uma perspectiva que entrelaçada ao ensino de uma língua pode demonstrar resultados significativos na formação de cidadãos críticosreflexivos, principalmente no âmbito profissional (SILVA; ABREU, 2016). Tais questionamentos foram necessários, visto que letramento é uma proposta considerada relativamente recente, sendo, portanto, muitas vezes, abordado em trabalhos científicos com outros significados distintos do seu conceito principal, como por exemplo, quando é trabalhado como sinônimo de alfabetização (ABREU; IRINEU, 2015).

Assim, questionou-se como o letramento é trabalhado no contexto do ensino técnico profissionalizante, se é estudado

\footnotetext{
${ }^{6}$ Codificação para Script 1 (S1).
} 
envolto ao processo de ensino e aprendizagem do espanhol, quais experiências estão relacionadas aos seus conceitos, e se existem lacunas nessa conjuntura. Além das perguntas elaboradas, determinaram-se também suas motivações, como expresso abaixo no Quadro 3.

Quadro 3 - Perguntas da pesquisa com suas respectivas motivações.

\begin{tabular}{|c|c|c|}
\hline$I D^{7}$ & Perguntas & Motivação \\
\hline$P 1^{8}$ & $\begin{array}{l}O \quad \text { conceito de } \\
\text { Letramentor é } \\
\text { abordador } \\
\text { relacionadorao } \\
\text { Ensino de Espanhol } \\
\text { comor Língua } \\
\text { Estrangeira (ELE)? }\end{array}$ & $\begin{array}{l}\text { Analisar se o conceito de } \\
\text { Letramento é trabalhado } \\
\text { no meio técnico } \\
\text { tecnológico federal do } \\
\text { Brasil e em quais } \\
\text { fundamentações teóricas } \\
\text { é estudado. }\end{array}$ \\
\hline$P 2$ & $\begin{array}{l}\text { Como é trabalhado } \\
\text { o estado da arte do } \\
\text { Letramento no } \\
\text { âmbito do ensino } \\
\text { técnico na rede } \\
\text { federal de educação } \\
\text { brasileira? }\end{array}$ & $\begin{array}{l}\text { Conhecer como o } \\
\text { conceito de Letramento é } \\
\text { trabalhado na rede } \\
\text { técnica profissionalizante } \\
\text { brasileira. }\end{array}$ \\
\hline P3 & $\begin{array}{l}\text { Há experiências de } \\
\text { ELE nos IFECT? } \\
\text { Quais? }\end{array}$ & $\begin{array}{l}\text { Explicitar as principais } \\
\text { experiências. }\end{array}$ \\
\hline$P 4$ & $\begin{array}{l}\text { Existem lacunas de } \\
\text { pesquisas na área } \\
\text { do Letramento com } \\
\text { uso de ELE nos } \\
\text { IFECT? }\end{array}$ & $\begin{array}{l}\text { Relacionar e elencar } \\
\text { possiveis lacunas de } \\
\text { pesquisas na área de } \\
\text { Letramento e ELE nos } \\
\text { IFCT. }\end{array}$ \\
\hline
\end{tabular}

Fonte: Elaborado pelos autores.

As buscas de materiais ocorreram apenas em ambientes online dos periódicos científicos classificados pelo sistema Qualis da Plataforma Sucupira ${ }^{9}$ - Capes na área de Letras e Linguística com estratos de qualidade (A1, A2, B1, B2, B3, B4, B5 ou C) ${ }^{10}$. O período de publicação dos artigos deveria estar entre 2008 e 2016, que resultou na identificação de 886 revistas em um universo de 3506 . Portanto, as revistas foram avaliadas e analisadas de forma

\footnotetext{
${ }^{7}$ ID é a codificação para Identificador (ID).

${ }^{8} \mathrm{P} 1$ é a codificação para o termo Pergunta 1 (P1) e assim consequentemente conforme as numerações em sequência para as demais perguntas (P2, P3 e P4).

${ }^{9} \mathrm{https}$ ///sucupira.capes.gov.br

${ }^{10}$ Qualis é um sistema de classificação que promove a avaliação de revistas, a partir de estratos de qualidade, nomeados de A1 - estrato mais elevado, A2, B1, B2, B3, $\mathrm{B} 4, \mathrm{~B} 5$ e $\mathrm{C}-\mathrm{o}$ estrato com peso zero.
}

a terem qualis no último ano em 2016, aquelas que perderam o qualis foram retiradas da base, tratando-se de um recorte do corpus proposto para esta investigação.

Dessa forma, cabe ainda destacar que o protocolo de RSL apresentou os critérios de inclusão e exclusão dos artigos, de tal forma a colaborar com as análises dos artigos no decorrer das fases da RSL e manter apenas aqueles contidos por algum critério de inclusão (Quadro 4).

Para o andamento da pesquisa, determinou que seriam analisadas apenas revistas que apresentassem artigos completos da área de Letras e Linguística, publicadas em periódicos nacionais na rede online, visto que tais critérios de inclusão garantem uma melhor acessibilidade desses trabalhos para a comunidade acadêmica. Logo, revistas com idiomas diferentes do português, revistas impressas e revistas com links corrompidos ou inexistentes foram descartadas da catalogação, perfazendo mais uma delimitação deste estudo.

A partir dos critérios de inclusão e exclusão definidos pelo protocolo da RSL foram encontradas 463 revistas com endereços online acessíveis. Desse modo, fez-se o acesso de cada link encontrado e colocou-se em prática a busca por intermédio dos scripts (Quadro 2).

Quadro 4 - Critérios de inclusão ou exclusão de materiais durante as etapas.

\begin{tabular}{|c|c|c|}
\hline Critérios & $I D$ & Descrição \\
\hline \multirow[t]{5}{*}{ Inclusão } & II & Artigos completos \\
\hline & $I 2$ & $\begin{array}{l}\text { Artigos publicados em periódicos } \\
\text { nacionais }\end{array}$ \\
\hline & $I 3$ & $\begin{array}{l}\text { Artigos publicados em periódicos } \\
\text { online }\end{array}$ \\
\hline & I4 & $\begin{array}{l}\text { Artigos indexados na área } \\
\text { Letras/Linguística }\end{array}$ \\
\hline & 15 & $\begin{array}{l}\text { Artigos publicados em periódicos } \\
\text { classificados com Qualis }\end{array}$ \\
\hline \multirow[t]{5}{*}{ Exclusão } & E1 & Artigos resumidos (short paper) \\
\hline & $E 2$ & Artigos impressos \\
\hline & E3 & $\begin{array}{l}\text { Artigos em idiomas diferentes do } \\
\text { português }\end{array}$ \\
\hline & E4 & $\begin{array}{l}\text { Link de acesso ao periódico } \\
\text { corrompido ou inexistente }\end{array}$ \\
\hline & E5 & $\begin{array}{l}\text { Portal do periódico não disponibiliza } \\
\text { ferramenta de busca }\end{array}$ \\
\hline
\end{tabular}

Fonte: Elaborado pelos autores. 
Além disso, por meio dos critérios estabelecidos, elaborou-se uma planilha para a organização dos dados. Nas colunas eram preenchidas, para cada fator específico das revistas em análise, dados como: ISSN, nome das revistas, estratos de qualidade durante os anos estabelecidos pela pesquisa, o meio em que se encontra para acesso (impresso ou digital), o endereço online e os motivos pelo qual permaneceu ou não na análise. Desse modo, a planilha criada foi compartilhada entre todos os integrantes da pesquisa e serão melhor detalhados os resultados nas seções seguintes.

\section{Resultados e discussão}

Conforme exposto no quadro 4, esta investigação lançou mão de alguns critérios para inclusão e exclusão das revistas a serem analisadas. Neste sentido, seguem os dados quantitativos de revistas que foram excluídas pela codificação já apresentada:

Quadro 5 - Total de revistas excluídas.

\begin{tabular}{|c|c|}
\hline CRITÉRIOS DE & $\begin{array}{c}\text { QUANTIDADE DE } \\
\text { RXCLUSATAS }\end{array}$ \\
\hline R1 & 0 \\
\hline$E 2$ & 36 \\
\hline E3 & 208 \\
\hline E4 & 52 \\
\hline E5 & 127 \\
\hline TOTAL DE REVISTAS & 423 \\
EXCLUÍDAS & \\
\hline
\end{tabular}

Fonte: Elaborado pelos autores.

Diante do exposto, com o universo de 886 revistas, resultou-se somente em 463 revistas analisadas por meio dos critérios de inclusão. Sendo assim, após a determinação das revistas incluídas para análise, utilizou-se da técnica de busca através das strings, em que, primeiramente, obteve-se o acesso aos endereços online das 463 revistas e, por conseguinte, a partir da ferramenta de busca que os sites ofereciam, procurava-se por: ("Letramento") AND ("Ensino técnico" OR "Ensino Profissionalizante" OR "Ensino técnico tecnológico" OR "Ensino Médio Integrado") AND ("Espanhol” OR "Língua
Espanhola" OR "Espanhol como língua estrangeira" OR "ELE") AND (year $>=2005$ ).

Logo, seguindo esse passo, das revistas analisadas, foram encontrados 0 (zero) resultados de trabalhos que abordam os seguintes eixos: Letramento, Ensino Técnico e Espanhol como Língua Estrangeira em conjuntura, como exposto no gráfico 1.

Gráfico 1 - Resultados encontrados.

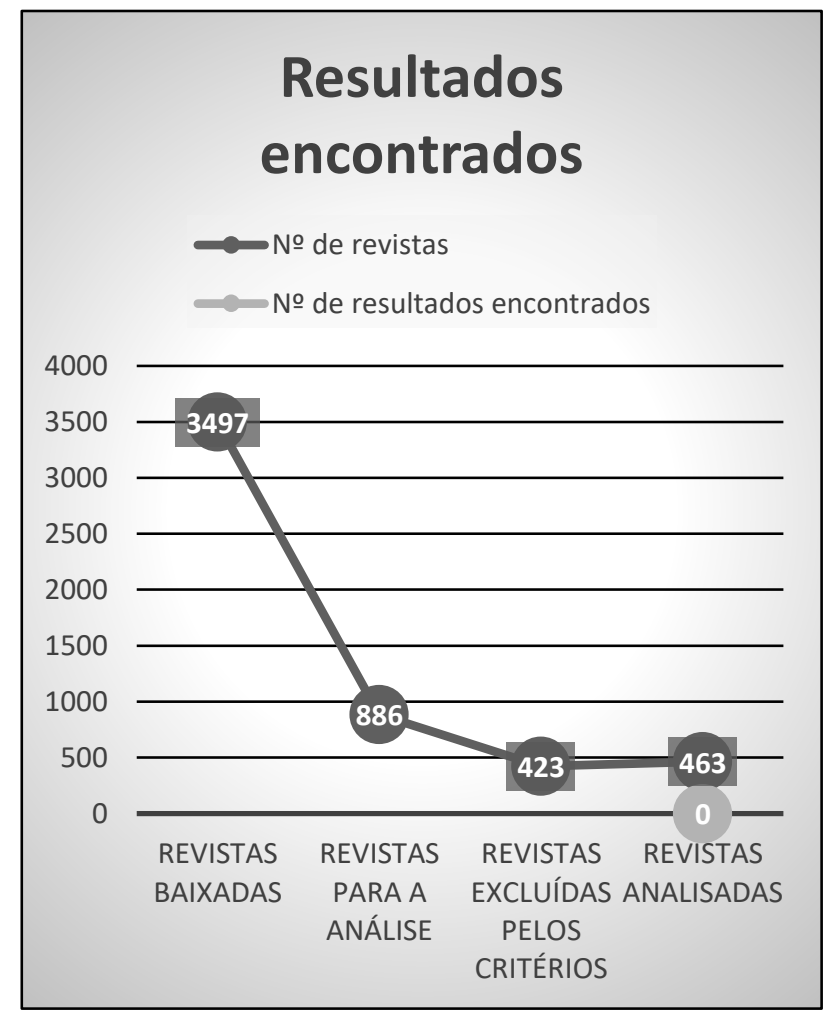

Fonte: Elaborado pelos autores.

Dessa forma, diante do resultado encontrado, diversos fatores entrelaçados ao cenário acadêmico-científico são postos a reflexão, tendo em vista que não foi encontrado nenhum resultado de revistas que abordem os temas relatados.

Primeiramente, analisando a perspectiva do Letramento como uma abordagem de ensino que prepara cidadãos para agir em sociedade em uma ótica crítica, questiona-se o porquê da proposta não ser abordado com frequência em trabalhos científicos da atualidade relacionado, principalmente, ao ensino de uma língua estrangeira, uma vez que se faz necessário também ao sistema educacional, já que possivelmente pode preparar cidadãos para a 
convivência sensata com diferentes contextos culturais. Vale ressaltar que nesse trabalho, optou-se pela Língua Espanhola, dado todo contexto envolto na implementação do seu ensino no Brasil.

Ainda nessa conjuntura, pode-se perceber que o ensino de uma língua estrangeira relacionada à uma abordagem de ensino que visa a formação de um cidadão crítico-reflexivo torna-se relevante também ao contexto do Ensino Técnico Profissionalizante, destacando-se o papel fundamental do cenário educacional na formação de bons profissionais para a sociedade.

Dessa forma, constata-se como o resultado encontrado de 0 (zero) trabalhos, pode ser uma lacuna em relação aos estudos no país. Principalmente, colocando-se em foco a fundamentação expressa pelas Diretrizes Curriculares Nacionais da Educação Básica (2013, p. 207):

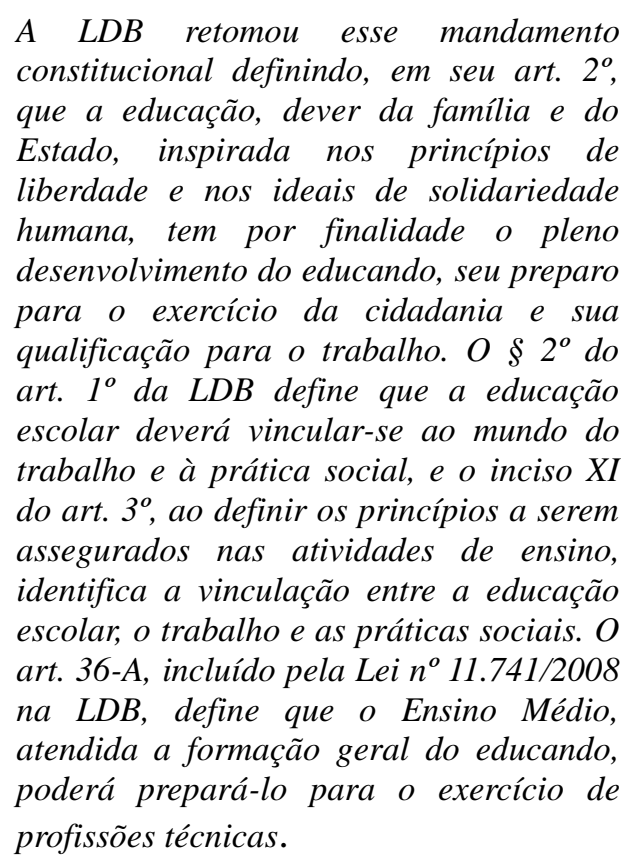

\section{Considerações finais}

O resultado encontrado na presente pesquisa e a lacuna descoberta a partir do mesmo, provoca uma reflexão quanto ao contexto cientifico-acadêmico do país em relação, essencialmente, aos termos determinados para esse estudo: Letramento,
Ensino Técnico e Espanhol. Tendo em vista, principalmente, que para a formação de bons profissionais para a sociedade torna-se necessário a implementação de metodologias de ensino voltadas para práticas sociais, entrelaçadas ao contato com diferentes culturas, com tecnologia e pesquisas científicas, entende-se que é preciso contornar lacunas expressa no cenário do ensino e da própria investigação científica.

Muito embora, acreditamos que a abordagem do letramento venha sim sendo utilizado pelos profissionais de linguagens do IF's, apenas os estudos por meio de pesquisas não ganharam o cenário de revistas conceituadas a nível nacional.

Dessa forma, este presente estudo, a partir do resultado de 0 (zero) trabalhos encontrados, tem também como finalidade incentivar uma maior produção de pesquisas voltadas para os principais eixos já citados, assim como também incentivar a maior publicação dessas pesquisas e possíveis implementações de formas de ensino que promovam o desenvolvimento da cidadania, em especial no contexto de globalização.

Por fim, ressalta-se que o presente estudo apresentou como principal ferramenta para pesquisa, o método da Revisão Sistemática de Literatura, a partir do andamento de cada passo determinado em seu protocolo. Dessa forma, a RSL pode ser caracterizada como uma metodologia que visa resultados objetivos.

\section{Referências}

ABREU, K.F. Concepções de leitura e de
texto subjacentes às provas de vestibular:
constatações e implicações para o ensino da
língua espanhola. Dissertação (Mestrado em
Linguística). Universidade Federal do Ceará.
Fortaleza, 2011.

ABREU, K.F; IRINEU, L.M. Pedagogia dos multiletramentos e ensino de espanhol como língua estrangeira: um estudo de caso no ensino médio técnico integrado Sertão Pernambucano. In: GOMES, A.T.; PONTES, V.O. Espanhol 
no Brasil: perspectivas teóricas e metodológicas. 2015.

ABREU, K.F.; IRINEU, L.M.; BAPTISTA, L.M.T.R. Letramento (s) e multiletramentos (s): conceitos, práticas e reflexões no ensino de língua portuguesa. In: Anais do VII Colóquio Nacional de Professores de Metodologia do Ensino de Língua Portuguesa e de Literatura, 2010. UERN, Pau dos Ferros, 2010.

ABREU, K. F; MORAIS, H. T. F; SILVA, M. R. V. Eventos de letramento (s) em português e em espanhol: a abordagem crítica na área de edificações. In: Anais do I Colóquio de Análise do Discurso (CNAD), 2014, Pau dos Ferros: UERN: 2014.

ALMEIDA FILHO, J. C. P. Aprendizagem e Ensino de Línguas em Contextos Tecnológicos. REVERTE: Revista de Estudos e Reflexões Tecnológicas da FATEC, Indaiatuba, v. 6, p.220-230, 2008.

BAPTISTA, L. M. T. R.. Traçando caminhos: letramento, letramento crítico e ensino de espanhol. In: BARROS, C.S.; COSTA, E.G.M.C. (Org.). Explorando o ensino. Espanhol: ensino médio. Brasilia: Secretaria da Educação Básica, MEC, 2010, v. 16, p. 119-.

BRASIL. Dispõe sobre o ensino da língua espanhola. Lei $\mathbf{n}^{\mathbf{0}} \mathbf{1 1 . 1 6 1}$, de 05 de agosto de $2005 . \quad$ Disponível em www.planalto.gov.br/ccivil.../Lei/L11161.htm. Acesso em: 06 abr. 2015.

Ministério da Educação. Lei de diretrizes e bases. Brasília, 1996. Disponível em:

http://www.planalto.gov.br/civil_03/Leis/L9394 .htm. Acesso em: 06 abr. 2015.

. Ministério da Educação. Orientações Curriculares Nacionais para o Ensino Médio. Linguagens, códigos e suas tecnologias. Conhecimentos de Espanhol. Secretaria da Educação Básica. Brasília: Mistério da Educação, 2006.
Concepções e diretrizes dos Institutos Federais. Brasília, Secretaria de Educação Profissional e Tecnológica, 2008. Disponível em: http://portal.ifrn.edu.br/insttucional/normas-eleis/concepção-e-diretrizes-dosinstitutos.pdf. Acesso em: 25 jan. 2015.

Diretrizes Curriculares Nacionais Gerais da Educação Básica. Ministério da Educação. Secretaria de Educação Básica. Diretoria de Currículos e Educação Integral. 2013.

Resolução nº de 20 de setembro de 2012. Conselho Nacional de Educação. Câmara de Educação Básica.

CASSANY, D. Tras las líneas. Sobre la lectura contemporánea. Barcelona: Editorial Anagrama, 2006.

GOETTENAUER, E. Espanhol: língua de encontros. In: SEDYCIAS, J. (org.). O ensino do espanhol no Brasil: passado, presente, future. São Paulo: Parábola Editorial, 2005.

KITCHENHAM, B. A.; CHARTERS, S. Guidelines for performing Systematic Literature Reviews in Software Engineering. Technical Report EBSE-2007-01, 2007. Disponível em: http://goo.gl/v6jvAZ. Acesso em: 24 fev. 2015.

MARSHALL, C.; BRERETON, P. Tools to Support Systematic Literature Reviews in Software Engineering: A Mapping Study. In: Empirical Software Engineering and Measurement, 2013 ACM/IEEE International Symposium on (pp. 296-299).

MORAIS, H.T.F; BENVENUTO, E.V.; ABREU, K.F.; BARRETO, L.S.V. Práticas de letramento na construção civil - Experiências do Projeto PIBEX Campus Salgueiro. In: OLIVEIRA, F.K.; ABREU, K.F (Org.). Métodos e pesquisas em educação. Kiron, Brasília. 2016.

OLIVEIRA, F. K.; GOMES, A. S. Revisão sistemática da literatura. In: OLIVEIRA, F. K.; 
(ABREU; OLIVEIRA; OLIVEIRA, 2017)

ABREU, K. F. (Org.). Experiências de Pesquisa em Educação e Tecnologia. Volume 2. Recife: Editora Pipa, 2016.

OLIVEIRA, F. K.; GOMES, A. S. Uma revisão sistemática da literatura sobre ferramentas de autoria de IMS-LD. In: Anais do Simpósio Brasileiro de Informática na Educação. 2015. p. 376. Disponível em: http://brie.org/pub/index.php/sbie/article/view/5190 Acesso em: 26 jan. 2016.

OLIVEIRA, J. K. C.; CORREIA, A.A.B.A; SOARES, L. A. F.; ABREU, K. F.. PRÁTICAS DE LETRAMENTO(S): vivenciando espaços de formação cidadã. In: IV Seminário Nacional do Ensino Médio, 2016, Mossoró. Anais do IV Senacem. Mossoró: UERN, 2016. v. 19. p. 3678-3689

SOARES, M. Letramento: um tema em três gêneros. 2.ed. 10 reimpr. - Belo Horizonte: Autêntica, 2005.

ROJO, R. Letramentos múltiplos: escola e inclusão social. São Paulo: Parábola, 2009.

ROJO, R. Multiletramentos na escola. São Paulo: Parábola, 2012.

SILVA, M. R. V.; ABREU, K. F.. Letramento(s) crítico (s): analisando as práticas letradas em língua espanhola de discentes técnicos em edificações. Revista Semiárido De Visu, v. 4, p. 41-49, 2016.

SOUZA, A.S. O Ensino de Língua Espanhola no Instituto Federal de Brasília: o dito, o feito e o pretendido. Dissertação de Metrado. Programa de Pós-Graduação em Linguística Aplicada. Universidade de Brasília, 2013.

STREET, B. Os novos estudos sobre o letramento: histórico e perspectivas. In: MARINHO, M.; CARVALHO, G.T. (Orgs.) Cultura escrita e letramento. Belo Horizonte: Editora UFMG, 2010. 